\title{
DEVELOPING A MODEL TO IMPROVE THE PREDICTION OF DAILY SOLAR RADIATION FOR THE PREDICTION OF REFERENCE EVAPOTRANSPIRATION
}

\begin{abstract}
Alzoheiry, A. M. ${ }^{1,2}$
$\underline{\text { ABSTRACT }}$

Three modification of the Hargreaves and Samani (HS) model were proposed to account for the effect of the atmospheric vapor on the prediction of the global solar radiation. The predicted values of the solar radiation using the three models and the values of the original $\mathbf{H S}$ model were compared to the measured solar radiation using root mean square error ( $\boldsymbol{R M S E})$, mean absolute bios error (MABE), mean bios error (MBE) and the T-test in pairs. The results showed that the first model $\mathbf{M 1}$, and the second model M2 performed better than the original $\mathrm{HS}$. The T-test results showed that there are no significant differences between the means values of the two models prediction and the mean value of the measured solar radiation. The $\mathbf{M B E}$ for both $\mathbf{M 1}$ and $\mathbf{M} 2$ indicates a tendency to slightly over estimate the solar values for $\mathbf{M 1}$, and a slight under estimation of the $\mathbf{M} 2$ prediction. The model M1 increased the values of the $\boldsymbol{E T O}$ predicted using the FPM than the original HS model and thus solved the problem of ETo under estimation by FPM. It is recommended to use M1 for application where over predictions is safer such as evapotranspiration prediction and use M2 where under prediction is safer such as solar radiation prediction for thermal solar application and solar collectors.
\end{abstract}

Keywords: Global solar radiation, prediction, Hargreaves and Samani, temperature based models, evapotranspiration.

\section{INTRODUCTION}

I rrigation scheduling is based mainly on the ability to predict the plant water requirements. This prediction is based on the prediction of the several models.

1 Dept. of Natural Resources and Agric. Eng., Faculty of Agric., Damanhour Univ., Egypt.

2 Dept. of Plant Production and Protection, Fac. of Agric. and Vet. Med., Qassim Univ., KSA. 
The models used to determine the $E T_{O}$ could be categorized as Water budget methods (Guitjens, 1982), Radiation based methods (Priestley and Taylor, 1972), Mass-transfer based methods (Harbeck, 1962), Temperature-based equations (Blaney-Criddle, 1962) and Compound methods such as Penman-Monteith method. Each category has its own data requirements and the accuracy of the prediction vary depending on the method and the available data. The most general and used way for the prediction of the $E T_{O}$ now is the FAO Penman-Monteith method (FPM). The method tacks into account all the metrological parameters involved in the evapotranspiration process such as solar radiation, wind speed, temperature, and humidity. The method also account for the soil type and the effect of the plant density and height (Allen et al. 1998). The prediction of the determination of the solar radiation is one of the parameters needed for the prediction of the $E T_{O}$. The accuracy of the solar radiation values affects the accuracy of the final $E T_{O}$ prediction. The best-case scenario is when measured data of solar radiation are available this gives the highest accuracy of the final prediction but this not always the case. Thornton, and Running (1999) pointed out the fact that most of the weather stations available reports the temperature data only while the number of the weather stations that actually recorded the solar radiation is very small. Several approaches were used to predict the solar radiation for a wide range of applications.

The prediction of the clear day daily solar radiation can be estimated according to the procedure of Majumdar et al. (1972). Boes (1981), Allen (1996) recalculated the value of the transmission index in the Majumdar procedure to account for the effect of the water vapor in the atmosphere. Besharat et al. (2013) reviewed the models used in the prediction of the global solar radiation. He divided the models into four groups. First, sunshine based models: empirical equation that predict the ratio of the sunshine duration such as Bakirci (2009), Katiyar and Pandey (2010), and El-Metwally (2005). Second, cloud based models such are models that based on the cloud cover data that can be determined by definite mean such as satellite imaging. A good example of these types of models is the Sabziparvar (2008) model cloud factors was obtained by using numbers of cloudy days in each month and cloud cover. Third, different metrological 
parameters models. Serval models were used to predict the global solar radiation using a wide range of metrological parameters such as humidity, precipitation, and pressure added to the traditional temperature and cloudiness such as the models of Ertekin and Yaldiz (1999), El-Metwally (2004), and Chen et al. (2004). The common characteristics of all these models is all of them are location based. Fourth, temperature based models are models that use the maximum and minimum daily temperature as an indicator to the cloud cover and the amount of water vapor in the atmosphere.

All these models are based on the idea that the presence of clouds will decrease the maximum daily temperature and increase the minimum daily temperature because the cloud reduce the amount of solar radiation reaching the ground and stop the ground emitted heat from leaving the atmosphere.

The first proposed model of this category is the Hargreaves and Samani model (Hargreaves and Samani 1982). Several modifications were made to the Hargreaves and Samani model such as the work of Mahmood and Hubbard (2002), Annandale et al. (2002), Allen (1997), Almorox et al. (2011) the modification ranged from recalibrating the constants in the original models to adding term that is based on other metrological data such as humidity.

The other approach used in the temperature model is the exponential model such as the model of Bristow and Campbell (1984) which had three empirical constants that represented the maximum possible clear day in the location and the approach of this value as the temperature difference increase. Also, several modifications have been made attempting to improve the accuracy of the model Goodin et al. (1999), Meza and Varas (2000).

Most of the attempts to modify the HS models to improve its prediction accuracy resulted in models that needs to be calibrated at every new location, which limits the use of the model or requires data that is not available to calibrate the models and determine the empirical its' coefficient values 
This work aims to test and evaluate the performance of three different modification of the Hargreaves and Samani model without adding extra data requirement other than the originally required maximum and minimum daily temperature and with minimizing the need for empirical constants that need location calibration. Then evaluate the effect of such modification on the prediction of the reference evapotranspiration.

\section{MATERIAL AND METHODS}

Three different modification of Hargreaves and Samani model were proposed to try to account for the effect of vapor in the atmosphere. The

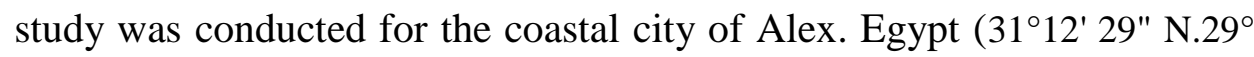
$58^{\prime} 32^{\prime \prime}$ E) during the year 2014. The maximum, minimum daily temperature and the global solar radiation on a horizontal surface were recorded for the location.

\section{The original model}

The original model of Hargreaves and Samani is based on the effect of clouds on the solar radiation reaching the ground. The model uses the difference between the maximum and minimum as an indicator to the amount of solar radiation reaching the ground. The $H S$ model is in the form:

Where:

$$
R=a I\left(T_{\max }-T_{\min }\right)^{0.5}
$$

$\mathrm{R}=$ the global solar radiation $\left(\mathrm{MJ} \mathrm{m}^{-2}\right.$ day $\left.^{-1}\right)$

$\mathrm{a}=$ constant first was set to 0.17 then Hargreaves proposed the value of 0.16 for inner location and 0.19 for costal locations (Hargreaves 1994).

$\mathrm{T}_{\max }$ and $\mathrm{T}_{\min }=$ the maximum and the minimum daily temperature $\left({ }^{\circ} \mathrm{C}\right)$ respectively.

$\mathrm{I}=$ extraterrestrial solar radiation $\left(\mathrm{MJ} \mathrm{m}^{-2}\right.$ day $\left.^{-1}\right)$

$I=\frac{24(60)}{\pi} G_{s c} d_{r}\left[\omega_{s} \sin (\varphi) \sin (\delta)+\cos (\varphi) \cos (\delta) \sin \left(\omega_{s}\right)\right]$

$\mathrm{G}_{\mathrm{sc}}=$ solar constant $=0.0820 \mathrm{MJ} \mathrm{m}^{-2} \mathrm{~min}^{-1}$,

$d_{r}=$ inverse relative distance Earth-Sun,

$d_{r}=1+0.33 \cos \left(\frac{2 \pi}{365} \mathrm{~J}\right)$

$\omega_{\mathrm{s}}=$ sunset hour angle $(\mathrm{rad})$, 
$\omega_{s}=\arccos [-\tan (\varphi) \tan (\delta)]$

$\varphi=$ latitude $(\mathrm{rad})$,

$\delta=$ solar declination $(\mathrm{rad})$,

$\delta=0.409 \sin \left(\frac{2 \pi}{365} J-1.39\right)$,

$\mathrm{J}=$ is the day of the year (Allen et al. 1998)

\section{Modification approach}

The proposed modifications depend on the same idea and takes the original model as a start, then adds a term to account for water vapor in the atmosphere. It is in the aim of this work not to use other constants that needs calibration in each location to make the resulting model as general as possible and in the same time it is in the aim of this work not to require additional metrological data other than the commonly available maximum and minimum daily temperature .

\section{The modified models}

\section{Model 1 MI}

The first modification added the ratio between the vapor pressure at the average temperature $\left(e_{T a v}\right)$ and the vapor pressure at the minimum daily temperature $\left(e_{T \min }\right)$ assuming that the relation between this value and the solar radiation is linear the resulting model was in the form

$$
R=a I\left(T_{\max }-T_{\text {min }}\right)^{0.5} \frac{e_{\text {Tav }}}{e_{\text {Tmin }}}
$$

Where:

$\mathrm{e}_{\mathrm{T}}=$ is the vapor pressure at temperature $\mathrm{T}$ and can be calculated as $e_{T}=0.6108 \exp \left[\frac{17.27 T}{237.3+T}\right]$

\section{Model 2 M2}

The second model added the same ratio to the original model but assuming that the relation between the ratio and the solar radiation is not linear.

\section{Model 3 M3}

$$
R=a I\left(\left(T_{\max }-T_{\min }\right) \frac{e_{T a v}}{e_{T \max }}\right)^{0.5}
$$

The third model attempted to add a term to cover the ratio of the difference between the vapor pressure at the average temperature and the vapor 
pressure at the minimum temperature to the difference between the vapor pressure at the maximum $\left(e_{T \max }\right)$ temperature and the vapor pressure at the minimum temperature.

$$
R=a I\left(\left(T_{\max }-T_{\min }\right) \frac{e_{T a v}-e_{T \min }}{e_{T \max }-e_{T \min }}\right)^{0.5}
$$

\section{Measurements}

The values of the actual global solar radiation were measured by Kipp and Zonen solar meter pyrometer. From August 2014 to August 2015 and the corresponding daily maximum and minimum temperatures were recorded

\section{Evaluating criteria}

The models including the original Hargreaves and Samani model were evaluated using the root mean square error $R M S E$, the mean absolute bias error $M A B E$, and the Mean bias error $M B E$ all these parameters were calculated according to Yorukoglu and Celik (2006). The resulting values of the solar radiation were tested using the $T$ test for paired samples to chick the significance of the deference of the averages of the models against the average of the measured values.

\section{Effect on reference evapotranspiration $\left(E T_{o}\right)$ prediction}

The resulting solar radiation values of the modified model and the original model were used to predict the $E T_{o}$ using the FAO Penman-Monteith method (FPM) and the cumulative yearly $E T_{o}$ were compared.

\section{RESULTS AND DISCUSSION}

\section{$\underline{\text { Results }}$}

\section{Global solar radiation:}

The values of the resulting predicted solar radiation were plotted against the measured values of the solar radiation in order to determine the coefficients in the trend lines between the two values. The values of the trend lines between $H S$ predicted values and the measured values had a slope of 1.03 value and an intersection of $3.8 \mathrm{MJ} \mathrm{m}^{-2}$ day ${ }^{-1}$ Fig (1). The values of the trend lines between $M 1$ predicted values and the measured values had a slope of 1.34 value and an intersection of $-0.62 \mathrm{MJ} \mathrm{m}^{-2}$ day ${ }^{-1}$ Fig (2). The values of the trend lines between $M 2$ predicted values and the measured values had a slope of 1.16 value and an intersection of $-0.34 \mathrm{MJ}$ 
$\mathrm{m}^{-2}$ day ${ }^{-1}$ Fig (3). The values of the trend lines between $M 3$ predicted values and the measured values had a slope of 0.66 value and an intersection of $0.56 \mathrm{MJ} \mathrm{m}^{-2}$ day $^{-1}$ Fig (4).

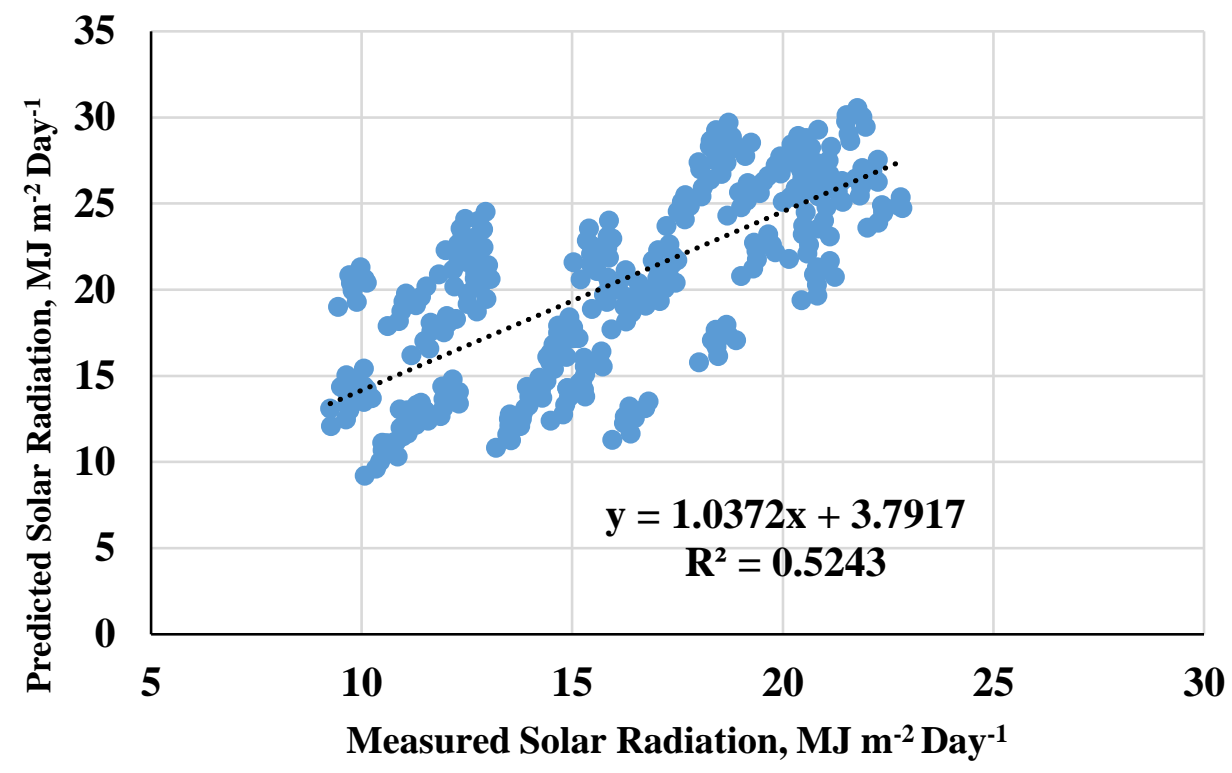

Fig. (1): The measured and predicted solar radiation for $H S$ model

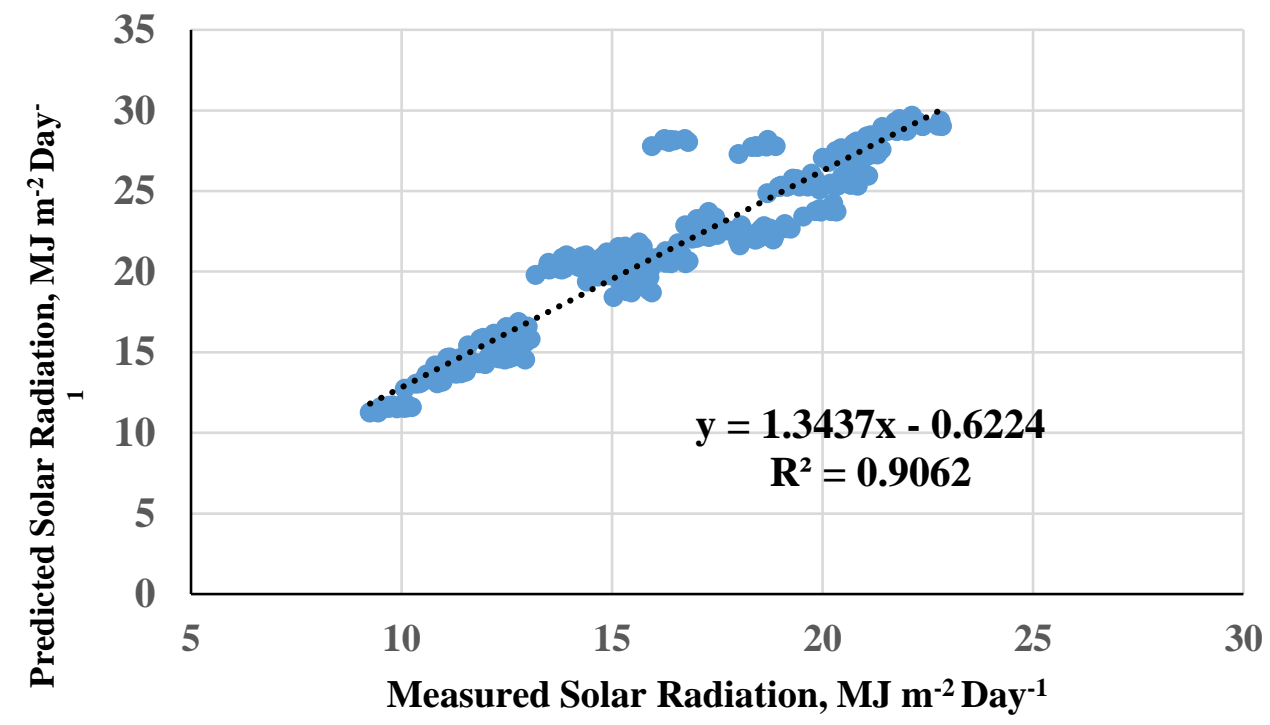

Fig. (2): The measured and predicted solar radiation for $M 1$ model 


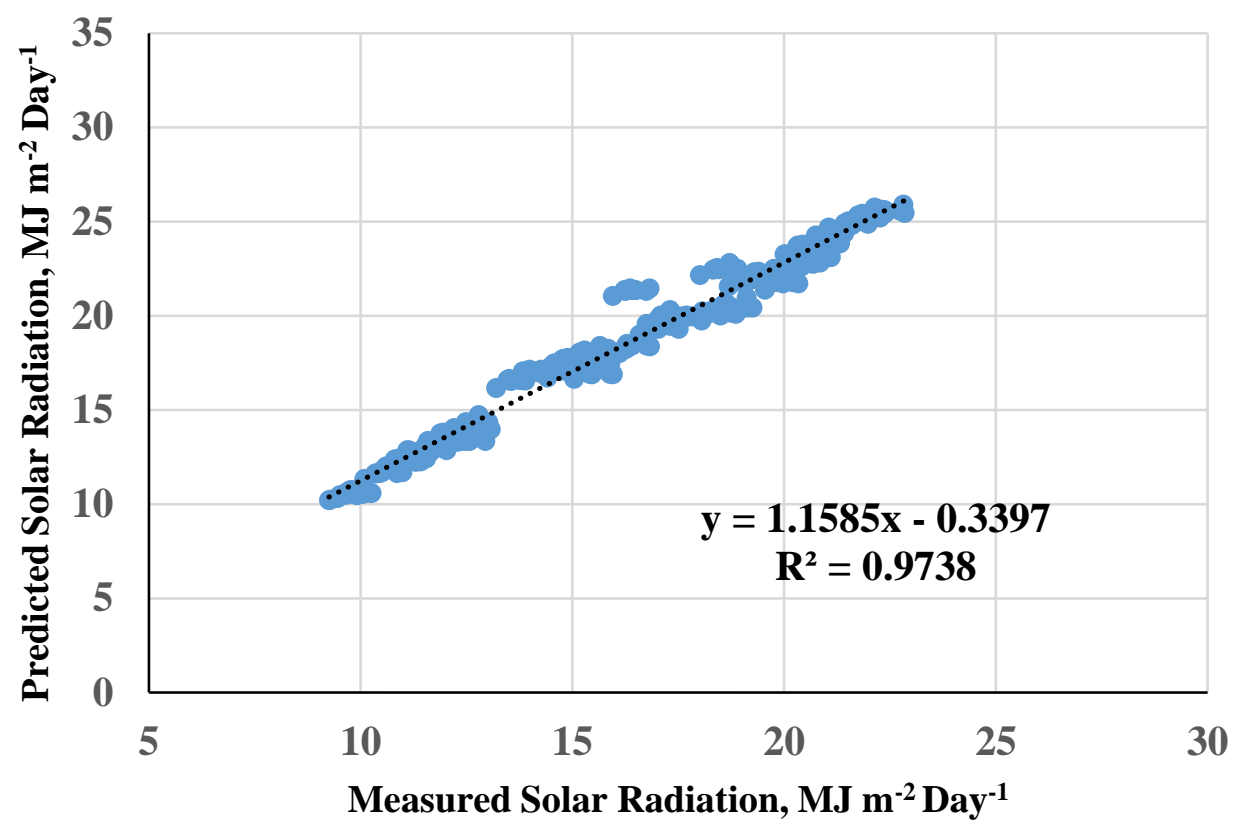

Fig. (3): The measured and predicted solar radiation for $M 2$ model

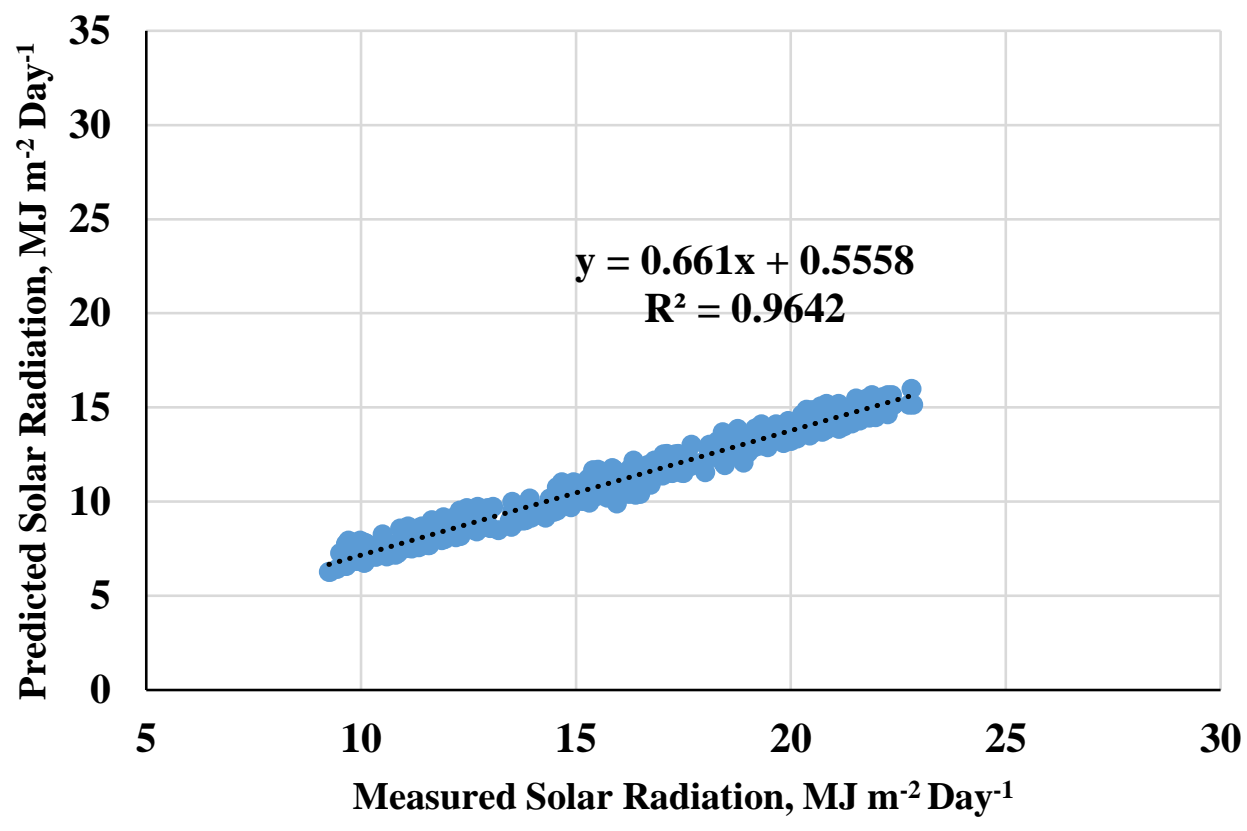

Fig. (4): The measured and predicted solar radiation for $M 3$ model 


\section{Statistical analysis:}

The values of the RMSE, MABE, and the $M B E$ for the original model and the three proposed models are shown in table (1). The original model has a tendency to under estimate the values of the values of the global solar radiation. The $M A B E$ of the $H S, M 1, M 2$, and $M 3$, was 4.34, 4.34, 3.72, and $8.88 \mathrm{MJ} \mathrm{m}^{-2}$ day $^{-1}$ respectively the results shows that the $M 1$ model had the same $M A B E$ as the $H S$ model and the $M 3$ model had a much higher $M A B E$ than the $H S$ model. The $M 2$ model performed better than the $H S$ model and the value of the $M A B E$ of this model was smaller than the $H S$ model.

Table (1): Summary of the statistical evaluation of the models $\left(\mathrm{MJ} \mathrm{m}^{-2} \mathrm{day}^{-1}\right)$

\begin{tabular}{|c|c|c|c|}
\hline & MABE & $\boldsymbol{R M S E}$ & $\boldsymbol{M B E}$ \\
\hline $\boldsymbol{H S}$ & 4.34 & 5.24 & 3.65 \\
\hline $\boldsymbol{M 1}$ & 4.34 & 5.40 & -1.34 \\
\hline $\boldsymbol{M 2}$ & 3.72 & 4.53 & 1.34 \\
\hline $\boldsymbol{M 3}$ & 8.88 & 9.69 & 8.88 \\
\hline
\end{tabular}

The same results were confirmed using the RMSE. The RMSE of the $H S$, $M 1, M 2$, and $M 3$, was $5.24,5.40,4.53$, and $9.69 \mathrm{MJ} \mathrm{m}^{-2}$ day $^{-1}$ respectively the results shows that the $M 1$ model had a slightly higher RMSE than the $H S$ model and the $M 3$ model had a much higher RMSE than the $H S$ model. The $M 2$ model performed better than the $H S$ model and the value of the $R M S E$ of this model was smaller than the $H S$ model.

The $M B E$ results confirmed that the $M 2$ model performed better than the original $H S$ model with a $M B E$ value of $1.34 \mathrm{MJ} \mathrm{m}^{-2}$ day $^{-1}$ compared to a value of $M B E$ of $3.65 \mathrm{MJ} \mathrm{m}^{-2} \mathrm{day}^{-1}$ for the $H S$ model. The results also confirmed that the $H S$ model performed better than the $M 3$ model that gave a $M B E$ value of $8.88 \mathrm{MJ} \mathrm{m}^{-2}$ day $^{-1}$. The results also showed that the $M 1$ (which was performing as the $H S$ model when evaluated using $M A B E$ and $R M S E$ ) performed better than the $H S$ model with a $M B E$ value of $-1.34 \mathrm{MJ}$ $\mathrm{m}^{-2}$ day $^{-1}$.

The $T$ test was conducted in paired samples with a hypothesis that there is a difference between the means of the measured values and the predicted values. The results of the $T$ test of the $H S$ model and the measured solar radiation values are shown in table (2). The mean value of the measured global solar radiation and the $H S$ predicted values was 19.22 and $15.57 \mathrm{MJ}$ 
$\mathrm{m}^{-2}$ day $^{-1}$ respectively and $P$ value of the test is less than the 0.01 this means that there is a significant deference between the two means. The mean of the model $M 1$ value was $20.56 \mathrm{MJ} \mathrm{m}^{-2}$ day $^{-1}$. The $T$ test $P$ value was 0.12 indicating an insignificant difference between the means of the values measured and predicted (table 3).

Table (2): $T$ test between the measured solar values and the $H S$ solar values

\begin{tabular}{rrr}
\hline & Measured & \multicolumn{1}{c}{$H S$} \\
\hline Mean & 19.22 & 15.57 \\
Variance & 30.33 & 14.84 \\
Observations & 365 & 365 \\
Pooled Variance & 22.59 & \\
Df & 728 & \\
t Stat & 3.56 & \\
$\mathrm{P}(\mathrm{T}<=\mathrm{t})$ one-tail & 0.000303 & \\
t Critical one-tail & 1.66 & \\
$\mathrm{P}(\mathrm{T}<=\mathrm{t})$ two-tail & 0.000605 & \\
$\mathrm{t}$ Critical two-tail & 1.99 & \\
\hline
\end{tabular}

Table (3): $T$ test between the measured solar values and the $M I$ solar values

\begin{tabular}{rrr}
\hline & Measured & \multicolumn{1}{c}{$M 1$} \\
Mean & 19.22 & 20.56 \\
Variance & 30.33 & 29.53 \\
Observations & 365 & 365 \\
Pooled Variance & 29.93 & \\
$\mathrm{df}$ & 728 & \\
$\mathrm{t}$ Stat & -1.14 & \\
$\mathrm{P}(\mathrm{T}<=\mathrm{t})$ one-tail & 0.129241 & \\
$\mathrm{t} \mathrm{Critical}$ one-tail & 1.66 & \\
$\mathrm{P}(\mathrm{T}<=\mathrm{t})$ two-tail & 0.258482 & \\
$\mathrm{t}$ Critical two-tail & 1.99 & \\
\hline
\end{tabular}

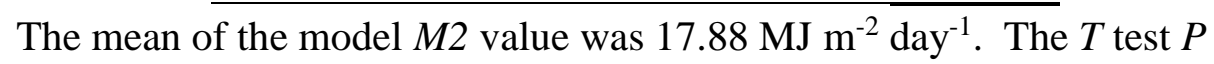
value was 0.11 indicating an insignificant difference between the means of the values measured and predicted (table 4). The mean of the model $M 3$ value was $10.34 \mathrm{MJ} \mathrm{m}^{-2}$ day $^{-1}$. The $T$ test $P$ value was less than 0.01 indicating a significant difference between the means of the values measured and predicted (table 5). 
Table (4): $T$ test between the measured solar values and the $M 2$ solar values

\begin{tabular}{rrr}
\hline & Measured & \multicolumn{1}{c}{ M2 } \\
\hline Mean & 19.22 & 17.88 \\
Variance & 30.33 & 20.44 \\
Observations & 365 & 365 \\
Pooled Variance & 25.39 & \\
$\mathrm{df}$ & 728 & \\
$\mathrm{t}$ Stat & 1.24 & \\
$\mathrm{P}(\mathrm{T}<=\mathrm{t})$ one-tail & 0.11013 & \\
$\mathrm{t}$ Critical one-tail & 1.66 & \\
$\mathrm{P}(\mathrm{T}<=\mathrm{t})$ two-tail & 0.22026 & \\
$\mathrm{t}$ Critical two-tail & 1.99 & \\
\hline
\end{tabular}

Table (5): $T$ test between the measured solar values and the $M 3$ solar values

\begin{tabular}{rrr}
\hline & Measured & \multicolumn{1}{c}{ M3 } \\
\hline Mean & 19.22 & 10.34 \\
Variance & 30.33 & 6.52 \\
Observations & 365 & 365 \\
Pooled Variance & 18.43 & \\
df & 728 & \\
t Stat & 9.59 & \\
$\mathrm{P}(\mathrm{T}<=\mathrm{t})$ one-tail & $1.91 \mathrm{E}-15$ & \\
$\mathrm{t}$ Critical one-tail & 1.66 & \\
$\mathrm{P}(\mathrm{T}<=\mathrm{t})$ two-tail & $3.83 \mathrm{E}-15$ & \\
$\mathrm{t}$ Critical two-tail & 1.99 & \\
\hline
\end{tabular}

The predicted $E T_{o}$ values using FPM equation with the solar radiation values predicted using $M 1$ (ETo-MI) and the predicted $E T_{o}$ values using FPM equation with the solar radiation values predicted using $H S$ (ETo-HS) are presented in fig (5). The results shows that the cumulative values of the $E T_{o}$ were higher using the $M I$ solar radiation values than the values predicted using the $H S$ solar radiation values. The total percentage of change at the end of the year was $19.33 \%$ higher than the original model. The predicted $E T_{o}$ values using FPM equation with the solar radiation values predicted using M2 (ETo-M2) and the predicted ETo values of ETo$H S$ are presented in fig (6). The predicted values shows that the model $M 2$ values of the $E T_{o}$ less than the original model in summer and higher values 
in winter. The total percentage of change at the end of the year was $2.34 \%$ lower than the original model.

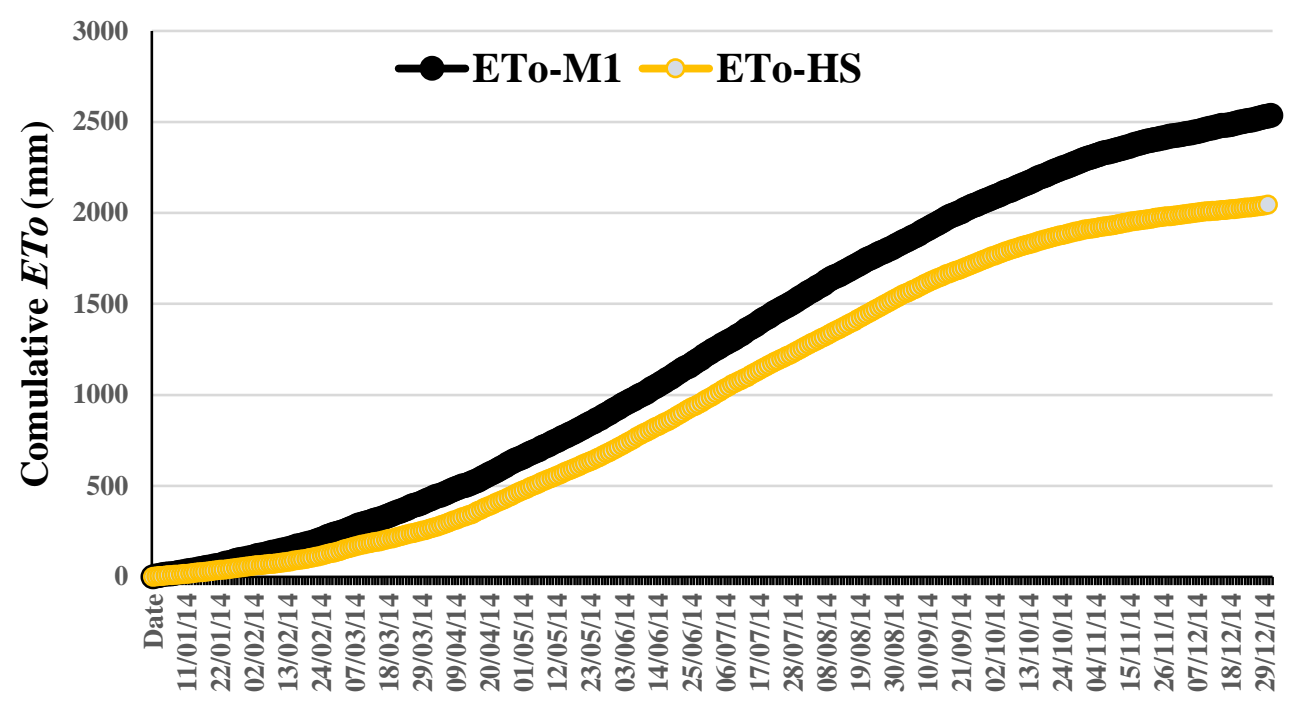

Fig. (5): Cumulative $E T_{o}$ predicted using the solar radiation values predicted using $M I$ and $H S$ respectively

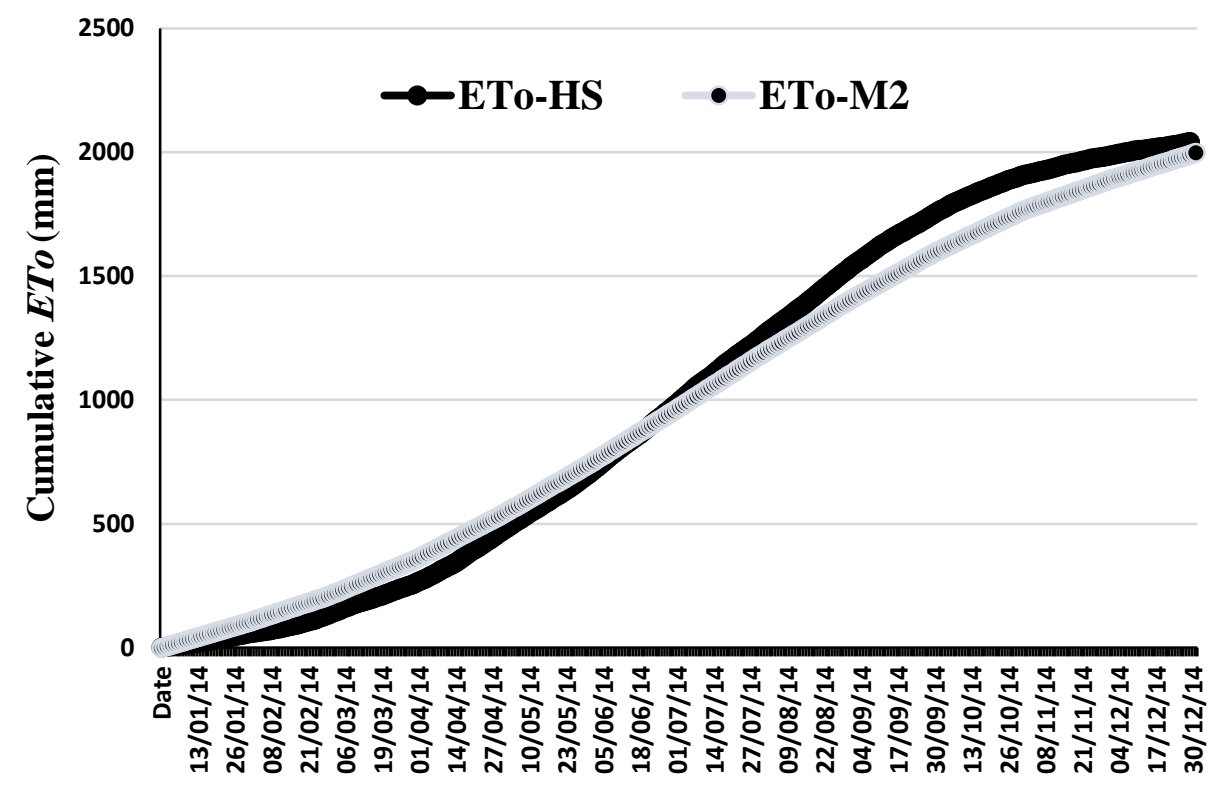

Fig. (6): Cumulative $E T_{o}$ predicted using the solar radiation values predicted using $M 2$ and $H S$ respectively 


\section{Discussion}

The three proposed models and the original model were compared to the measured values of the daily global solar radiation. The results of the mean absolute bias error $M A B E$ and the root mean square error RMSE indicated that the performance of the model $M 2$ was better than the original $H S$ model. The values of the Mean bias error $M B E$ indicate that the model $M I$ is also better than the $H S$ model in its' prediction. These results were confirmed by the $T$ test which showed that the prediction of the two models had means that are insignificantly different than the measured values. These results indicate that the vapor in the atmosphere has an effect on the amount of solar radiation reaching the ground and a term expressing the vapor pressure in the atmosphere can improve the prediction of the original $H S$ model. These results agree with the results of Winslow et al. (2001) and Almorex et al. (2011) both proposed adding terms to calculate the vapor pressure in the models used in predicting the daily global solar radiation to improve its performance. The results also showed that the term added to the third model did not improve the model prediction this may be because of the costal nature of the location which made the difference between the vapor pressure at the maximum, the average, and the minimum temperature small. The results also indicate that a single statistical parameter is not sufficient to evaluate the model performance, and that different parameters can give different indication this is similar to what Willmott and Matsuura (2005) reported that the RMSE tend to exaggerate the model error when some values of the prediction have bigger error values. The results also show that the RMSE, MABE and $M B E$ can give incorrect indication about the model prediction and the results needs to be verified by a $T$ test. The solar radiation values predicted using the model $M I$ increased the values of the ETo values predicted using the FPM equation this could be consider an improvement in arid and semiarid areas where the FPM tend to underestimate the values of the $E T_{o}$ as reported by Benli, et al. (2010), they reported that FPM underestimates the values of the $E T_{o}$ under high radiation conditions. This may be caused by the tendency of the $H S$ to underestimate the values of the solar radiation at the higher values of radiation. 


\section{CONCLUSION}

Three modification of the $H S$ model were proposed to account for the effect of the atmospheric vapor on the prediction of the global solar radiation. The predicted values of the solar radiation using the three models and the values of the original $H S$ model were compared to the measured solar radiation using RMSE, MABE, MBE and the $T$-test in pairs. The $M 1$, and $M 2$ model performed better than the original $H S$ and the $T$ - test results showed that there are no significant differences between the means values of the two models prediction and the mean value of the measured solar radiation. The $M B E$ for both $M 1$ and $M 2$ indicates a tendency to slightly over estimate the solar values for $M 1$, and a slight under estimation of the $M 2$ prediction. The model $M I$ increased the values of the $E T_{o}$ predicted using the FPM than the original HS model and thus solved the problem of $E T_{o}$ under estimation by FPM. It is recommended to use $M 1$ for application where over predictions is safer such as evapotranspiration prediction and use $M 2$ where under prediction is safer such as solar radiation prediction for thermal solar application and solar collectors.

\section{REFERENCES}

Allen, R. G. (1996). Assessing integrity of weather data for reference evapotranspiration estimation. Journal of Irrigation and Drainage Engineering, 122(2), 97-106.

Allen, R. G. (1997). Self-calibrating method for estimating solar radiation from air temperature. Journal of Hydrologic engineering, 2(2), 5667.

Allen, R. G., Pereira, L. S., Raes, D., and Smith, M. (1998). Crop evapotranspiration-Guidelines for computing crop water requirements-FAO Irrigation and drainage paper 56. Fao, Rome, 300(9), D05109.

Almorox, J., Hontoria, C., and Benito, M. (2011). Models for obtaining daily global solar radiation with measured air temperature data in Madrid (Spain). Applied Energy, 88(5), 1703-1709.

Annandale, J., Jovanovic, N., Benade, N., and Allen, R. (2002). Software for missing data error analysis of Penman-Monteith reference evapotranspiration. Irrigation Science, 21(2), 57-67. 
Bakirci, K. (2009). Correlations for estimation of daily global solar radiation with hours of bright sunshine in Turkey. Energy, 34(4), 485-501.

Benli, B., Bruggeman, A., Oweis, T., and Üstün, H. (2010). Performance of Penman-Monteith FAO56 in a semiarid highland environment. Journal of Irrigation and Drainage Engineering, 136 (11), 757-765.

Bristow, K. L., and Campbell, G. S. (1984). On the relationship between incoming solar radiation and daily maximum and minimum temperature. Agricultural and forest meteorology, 31(2), 159-166.

Besharat, F., Dehghan, A. A., and Faghih, A. R. (2013). Empirical models for estimating global solar radiation: A review and case study. Renewable and Sustainable Energy Reviews, 21, 798-821.

Boes, E. C. (1981). "Chapter 2: Fundamentals of solar radiation." Solar energy handbook, J. F. Kreider and F. Kreith, eds., McGraw-Hili Book Co., New York, N.V.

Blaney, H. F., and Criddle, W. D. (1962). Determining consumptive use and irrigation water requirements (No. 1275). US Department of Agriculture.

Chen, R., Ersi, K., Yang, J., Lu, S., and Zhao, W. (2004). Validation of five global radiation models with measured daily data in China. Energy Conversion and Management, 45(11-12), 1759-1769.

Ertekin, C., and Yaldız, O. (1999). Estimation of monthly average daily global radiation on horizontal surface for Antalya (Turkey). Renewable Energy, 17(1), 95-102.

El-Metwally, M. (2004). Simple new methods to estimate global solar radiation based on meteorological data in Egypt. Atmospheric Research, 69(3-4), 217-239.

El-Metwally, M. (2005). Sunshine and global solar radiation estimation at different sites in Egypt. Journal of Atmospheric and SolarTerrestrial Physics, 67(14), 1331-1342. 
Goodin, D. G., Hutchinson, J. M. S., Vanderlip, R. L., and Knapp, M. C. (1999). Estimating solar irradiance for crop modeling using daily air temperature data. Agronomy Journal, 91(5), 845-851.

Guitjens, J. C. (1982). Models of alfalfa yield and evapotranspiration. Journal of the irrigation and drainage division, 108(3), 212-222.

Harbeck, G. E. (1962). A practical field technique for measuring reservoir evaporation utilizing mass-transfer theory. US Government Printing Office.

Hargreaves, G. H., and Samani, Z. A. (1982). Estimating potential evapotranspiration. Journal of the Irrigation and Drainage Division, 108(3), 225-230.

Hargreaves, G. H. (1994). Simplified coefficients for estimating monthly solar radiation in North America and Europe. Dept. Paper. Departmental of Biological and Irrigation Engineering, Utah State University, Logan

Katiyar, A. K., and Pandey, C. K. (2010). Simple correlation for estimating the global solar radiation on horizontal surfaces in India. Energy, 35(12), 5043-5048.

Mahmood, R., and Hubbard, K. G. (2002). Effect of time of temperature observation and estimation of daily solar radiation for the Northern Great Plains, USA. Agronomy Journal, 94(4), 723-733.

Majumdar, N. C., Mathur, B. L., and Kaushik, S. B. (1972). Prediction of direct solar radiation for low atmospheric turbidity. Solar Energy, 13(4), 383-394.

Meza, F., and Varas, E. (2000). Estimation of mean monthly solar global radiation as a function of temperature. Agricultural and Forest Meteorology, 100(2-3), 231-241.

Priestley, C. H. B., and Taylor, R. J. (1972). On the assessment of surface heat flux and evaporation using large-scale parameters. Monthly weather review, 100(2), 81-92. 
Sabziparvar A. A. (2008). A simple formula for estimating global solar radiation in central arid deserts of Iran. Renewable Energy 2008;33:1002-10.

Thornton, P. E., and Running, S. W. (1999). An improved algorithm for estimating incident daily solar radiation from measurements of temperature, humidity, and precipitation. Agricultural and Forest Meteorology, 93(4), 211-228.

Willmott, C. J., and Matsuura, K. (2005). Advantages of the mean absolute error (MAE) over the root mean square error (RMSE) in assessing average model performance. Climate research, 30(1), 79-82.

Winslow, J. C., Hunt Jr, E. R., and Piper, S. C. (2001). A globally applicable model of daily solar irradiance estimated from air temperature and precipitation data. Ecological Modelling, 143(3), 227-243.

Yorukoglu, M., and Celik, A. N. (2006). A critical review on the estimation of daily global solar radiation from sunshine duration. Energy Conversion and Management, 47(15-16), 2441-2450.

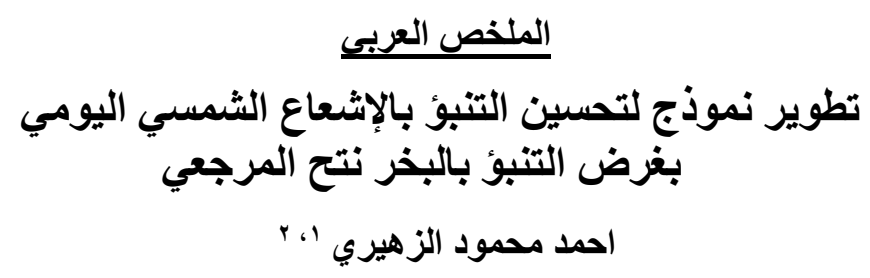

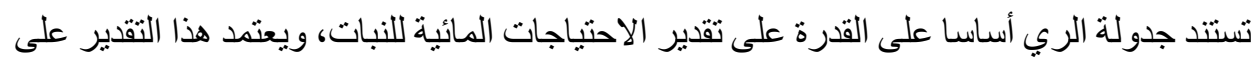

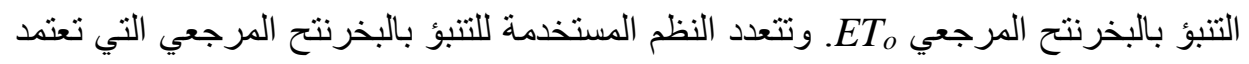

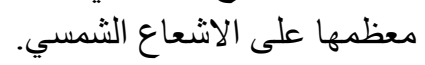

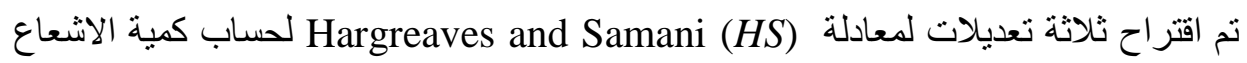

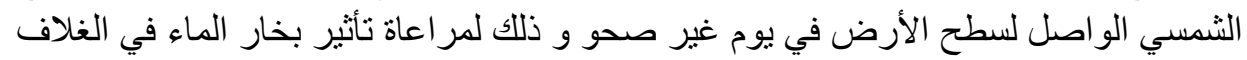

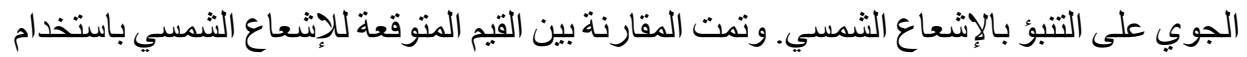

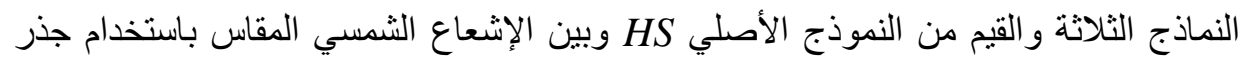

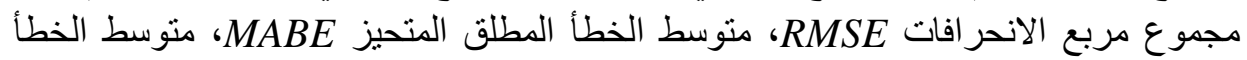
المتحيز MBE و اختبار T في أزواج.

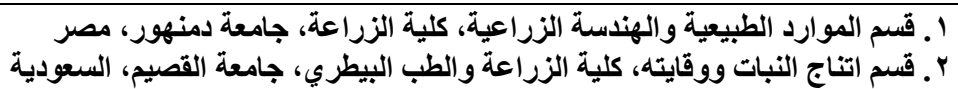


أظهر النموذج الأول M1، و النموذج الثاني M2 أداءً أفضل من النموذج الأصلي HS و

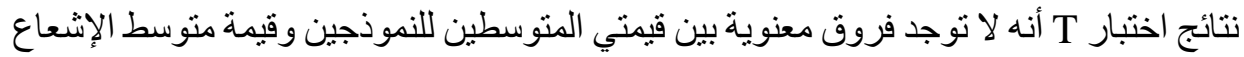

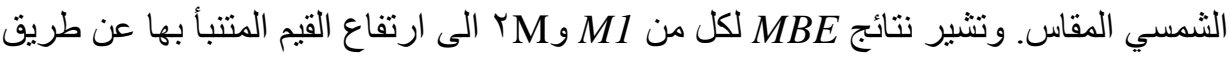
M1 عن القيم المقاسة و انخفاض القيم المتنبأ بها عن طريق M2 عن Mن القيم المقاسة.

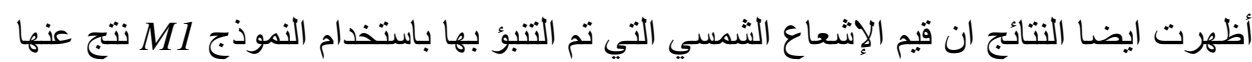
زيادة في قيم ET تقدير ETo للمناطق القاحلة وشبه الجافة و التي تميل فيها معادلة بنمان مونتيث لتقدير اقل من أن الحقيقي لقيم البخرنتح المرجعي.

يوصى البحث باستخدام M1 للتطبيقات حيث تكون التنبؤات الزائدة أكثر أمانًا مثل التنبؤ بالبخر

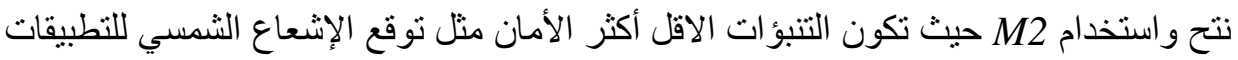
الثمسية الحر ارية ومجمعات الطاقة الثمسية. 